\title{
RESISTÊNCIA NATURAL DA MADEIRA DE Corymbia maculata (Hook.) K.D.Hill \& L.A.S. Johnson A FUNGOS E CUPINS XILÓFAGOS, EM CONDIÇÕES DE LABORATÓRIO ${ }^{1}$
}

\author{
Juarez Benigno Paes ${ }^{2}$
}

\begin{abstract}
RESUMO - A pesquisa teve o objetivo de avaliar a resistência natural da madeira de Corymbia maculata a fungos e a cupins xilófagos, em condições de laboratório. De peças radiais (tábuas) que continham o cerne e o alburno intactos foram retirados corpos-de-prova de 2,00 x 2,00 x $1,00 \mathrm{~cm}$, com a menor dimensão na direção tangencial (ensaio com fungos), e de 2,54 x 2,00 x 0,64 cm, com a maior dimensão na direção das fibras (ensaio com cupins), em quatro posições na direção medula-casca. As amostras foram submetidas à ação dos fungos Postia placenta, Neolentinus lepideus e Polyporus fumosus por 12 semanas, ou à ação de cupins do gênero Nasutitermes por 30 dias. Constatou-se que a resistência da madeira ao apodrecimento foi dependente da posição na direção medula-casca e dos fungos utilizados. As amostras retiradas nas posições mais externas do tronco foram mais deterioradas que as internas. Dentro de cada posição, os fungos causaram deterioração semelhante à madeira, exceto para a posição mais externa (alburno), em que o fungo P. fumosus causou menos deterioração que os demais. De modo geral, a madeira de $C$. maculata foi altamente resistente (posições internas) ou resistente (posições externas) aos fungos ensaiados. Somente para o fungo N. lepideus a posição mais externa foi moderadamente resistente. Quanto aos cupins, a resistência da madeira não foi afetada pela posição na direção medula-casca e apresentou uma baixa perda de massa para as posições analisadas. Além disto, os cupins causaram somente desgaste superficial à madeira, e morreram durante o ensaio, o que permitiu classificar a madeira de C. maculata como resistente aos cupins ensaiados.
\end{abstract}

Palavras-chave: Resistência natural, Corymbia maculata, fungos e cupins xilófagos.

\section{WOOD NATURAL RESISTANCE OF Corymbia maculata (Hook.) K.D.Hill \& L.A.S Johnson TO WOOD DESTROYING FUNGI AND TERMITES, UNDER LABORATORY TESTS}

\begin{abstract}
This research evaluated the natural resistance of Corymbia maculata wood to wood-destroying fungi and termites, under laboratory tests. Radial pieces (boards), containing intact heartwood and sapwood were transformed into test samples measuring $2.00 \times 2.00 \times 1.00 \mathrm{~cm}$, with the smallest measure in tangential direction (fungi assay) and measuring $2.45 \times 2.00 \times 0.64 \mathrm{~cm}$; with the largerst measure fiberwise (termite assay), in four positions from pith to bark. The samples were submitted to fungi Postia placenta, Neolentinus lepideus and Polyporus fumosus action for 12 weeks or to Nasutitermes sp. action for 30 days. Wood decay resistance was found to be dependent on the position pith to bark and on the fungus. The wood samples in the most external positions were more deteriorated. Inside of each position, the fungi caused similar deterioration, except for the most external position (sapwood) where the P. fumosus caused less deterioration than other tested fungi. In general, $\boldsymbol{C}$. maculata wood was highly resistant (internal positions) or resistant (external positions) to the fungi. Just for the Neolentinus lepideus, the external position was classified as moderately resistante. The tested wood to termite resistance was not affected by position in the pith to bark direction and showed weight loss for all-analyzed positions. Besides, it was affected only superficially and the termites died during the assay. The C. maculata wood was classified as resistant to the termites assayed.
\end{abstract}

Key words: $\quad$ Natural resistance, Corymbia maculata, wood-destroying fungi and termites.

1 Recebido para publicação em 6.6.2000.

Aceito para publicação em 3.12.2002.

2 Prof. da Universidade Federal da Paraíba - UFPB/CSTR/DEF - Campus VII - Caixa Postal, 64, 58700-970 Patos-PB, $<$ jbp2@uol.com.br>. 


\section{INTRODUÇÃO}

A cultura do eucalipto foi introduzida no Brasil em 1904, para fornecer lenha às locomotivas da Companhia Paulista de Estradas de Ferro (Rezende, 1981; Aguiar, 1986). Em Minas Gerais sua implantação deu-se em 1940, para suprir o setor siderúrgico de carvão vegetal. Mais tarde, com a lei dos incentivos fiscais, a eucaliptocultura teve grande expansão em todo o território nacional (Rezende, 1981; Della Lucia, 1986; Silva, 1993). Atualmente, o Brasil é o país com a maior área implantada com eucalipto no mundo, estimada em 3.380 .000 ha (Silva, 1993). Dada à grande variação genética entre espécies, o eucalipto pode ser utilizado como madeira na construção civil, na indústria de móveis e na produção de portas, janelas, lambris, assoalhos etc. (Vital \& Della Lucia, 1986). Em função da gama de utilização do eucalipto, algumas empresas, tradicionalmente produtoras de celulose e papel ou de carvão vegetal, passaram a manejar suas florestas para o uso múltiplo (Silva, 1993; Couto, 1995). Por causa de sua disponibilidade, taxa de crescimento, forma do fuste e propriedades físico-mecânicas, o eucalipto apresenta boas perspectivas como sucedânea de espécies nativas (Lelles \& Rezende, 1986).

Dentro do gênero Eucalyptus há várias espécies produtoras de madeiras resistentes ao ataque de organismos xilófagos. Porém, Lelles \& Rezende (1986) afirmam que as cultivadas no Brasil, inclusive a madeira de cerne da maioria das espécies, não apresentam resistência natural satisfatória. Os autores relataram também que há poucos estudos relativos à resistência natural das diversas espécies de Eucalyptus cultivadas no Brasil.

A resistência da madeira à deterioração é a capacidade inerente à espécie de resistir à ação de agentes deterioradores, incluindo os agentes biológicos e os físicos e químicos. No entanto, em virtude da frequiência e da importância econômica, a resistência natural é normalmente entendida como referente aos agentes biológicos (Willeitner, 1984).

A resistência à biodeterioração é atribuída à presença de certas substâncias no lenho, como taninos e outras substâncias fenólicas complexas tóxicas a fungos e a insetos xilófagos (Hunt \& Garratt, 1967; Findlay, 1985; Lelles \& Rezende, 1986).

As árvores de crescimento rápido têm, em geral, menos resistência natural que as de crescimento lento (Scheffer, 1973; Panshin \& De Zeeuw, 1980). Hillis
(1984) concorda com esses autores, e afirma que uma rápida taxa de crescimento está relacionada à redução no teor de extrativos na madeira de Corymbia sp.

Em geral, há variação na resistência natural entre o cerne interno e o externo. Em praticamente todas as árvores em que essa diferença foi encontrada a região central do cerne é menos resistente à decomposição que a região externa, próxima ao alburno (Scheffer, 1973; Panshin \& De Zeeuw, 1980).

A variação em resistência dentro da árvore está correlacionada à concentração dos extrativos tóxicos presentes no lenho. Isto é um dos fatores que contribui para a discrepância dos resultados obtidos nos testes de durabilidade da madeira (Lepage, 1986), pois em muitos trabalhos os pesquisadores utilizam, como indicado pela ASTM D-2017, apenas a madeira do cerne externo. Willeitner (1984) faz várias críticas ao método recomendado por essa norma. $\mathrm{O}$ autor afirma que em virtude da variação na madeira todo o cerne deve ser avaliado.Todavia, a madeira não é constituída somente de cerne, podendo haver grande proporção de alburno em peças empregadas para vários fins.

Este estudo teve o objetivo de avaliar a resistência natural da madeira de Corymbia maculata a fungos xilófagos e a cupins subterrâneos do gênero Nasutitermes, em condições de laboratório.

\section{MATERIAL E MÉTODOS}

\subsection{Madeira de Eucalipto Utilizada}

Utilizou-se madeira de Corymbia maculata obtida de plantio com 21 anos da Universidade Federal de Viçosa (UFV), localizado na Silvicultura, em Viçosa-MG.

A opção em utilizar o C. maculata deveu-se à sua disponibilidade no Laboratório de Propriedades Físicas e Mecânicas da Madeira da UFV, por observar que o seu alburno foi atacado por coleobrocas (Lyctus sp.), à sua utilização como moirões e postes e em construções diversas, nos meios rural e urbano, uma vez que estes usos expõem a madeira a alto risco de ataque de organismos xilófagos.

\subsection{Confecção dos Corpos-de-Prova}

Selecionou-se uma peça radial (tábua) que continha o cerne e o alburno intactos. Da tábua selecionada 
retirou-se uma secção isenta de defeitos, correspondente à região intermediária ao DAP, de aproximadamente $50 \mathrm{~cm}$ de comprimento. A secção foi subdividida em oito partes radiais, diametralmente opostas e de mesma dimensão, que foram agrupadas duas a duas e identificadas conforme sua posição em relação à medula. Deste modo, toda a madeira foi representada, e não somente o cerne, conforme recomendado por Willeitner (1984) e ASTM D-2017 (1994).

Para homogeneizar as dimensões das amostras no sentido radial, elas foram aplainadas para 2,00 cm. Em seguida, foram transformadas em corpos-de-prova de $2,00 \times 2,00 \times 1,00 \mathrm{~cm}$, com a menor dimensão no sentido tangencial (ensaio com fungos), ou de 2,54 x 2,00 x $0,64 \mathrm{~cm}$, com a maior dimensão no sentido das fibras (ensaio com cupins).

Após a obtenção dos corpos-de-prova selecionaramse, de cada secção, três amostras para o ensaio com fungos e quatro para o ensaio com cupins. Determinaram-se o volume e a massa de cada amostra, como recomendado pela ASTM D-1413 (1994), e os valores foram utilizados no cálculo da densidade da madeira e da perda de massa sofrida pelos corpos-de-prova submetidos aos ensaios.

\subsection{Ensaio de Resistência Natural a Fungos Xilófagos}

O ensaio foi executado segundo a ASTM D-2017 (1994), sendo seis amostras por tratamento (fungos testados/posições na madeira). Para proporcionar a deterioração à madeira foram empregadas culturas puras dos fungos Postia placenta (Madison 698, USDA/FS/ FPL, Estados Unidos, obtida em 15/5/1989), Neolentinus lepideus (44J) e Polyporus fumosus (496A), obtidas do Forintek Canada Corporation, Canadá, em 16/8/1995.

As culturas foram armazenadas sob refrigeração e repicadas para placas de Petri, contendo meio de cultura à base de malte-ágar. Após duas semanas, quando já se encontravam bem desenvolvidos nas placas, os fungos foram inoculados nos frascos.

Neste experimento, empregaram-se frascos de $500 \mathrm{ml}$ de capacidade, preenchidos com $350 \mathrm{~g}$ de solo, cuja umidade foi ajustada pela adição de $80 \mathrm{ml}$ de água destilada. Em seguida, foram adicionados dois alimentadores de Pinus sp., e os frascos foram esterilizados a $121 \pm 2{ }^{\circ} \mathrm{C}$, durante 1 hora.

Depois de inoculados, como indicado pela ASTM D-2017 (1994), e as culturas fúngicas estarem bem desenvolvidas nos alimentadores, adicionaram-se dois corpos-de-prova, previamente esterilizados, por frascos. $\mathrm{O}$ ensaio foi em sala climatizada $\left(27 \pm 1{ }^{\circ} \mathrm{C}\right.$ e $65 \pm 5 \%$ de umidade relativa), por 12 semanas.

Para avaliar a resistência da madeira de C. maculata aos fungos xilófagos, computou-se a perda de massa, que foi avaliada com base na massa anidra dos corpos-deprova, tomada antes e após os ensaios. As perdas foram corrigidas em função de amostras submetidas às mesmas situações descritas, porém sem a presença dos fungos.

No Quadro 1 encontram-se transcritas as classes de resistência para madeira, conforme indicações da ASTM D-2017 (1994).

\subsection{Ensaio de Resistência a Cupins Subterrâneos}

O ensaio foi executado segundo a norma ASTM D3345 (1994), com os ajustes sugeridos por PAES (1997). Deste modo, o ensaio foi montado em frascos de $500 \mathrm{ml}$ de capacidade, preenchidos com $200 \mathrm{~g}$ de areia, cuja umidade foi corrigida para $75 \%$ da capacidade de retenção, pela adição de $38 \mathrm{ml}$ de água destilada. Em cada frasco foram adicionados um corpo-de-prova e $1 \pm 0,05 \mathrm{~g}$ de cupins subterrâneos do gênero Nasutitermes, equivalendo a aproximadamente 350 indivíduos. Para evitar a fuga e permitir a respiração dos cupins, os frascos foram tampados frouxamente.

Foram montadas oito repetições para cada posição na direção medula-casca. $\mathrm{O}$ ensaio permaneceu em sala climatizada $\left(28 \pm 2{ }^{\circ} \mathrm{C}\right.$ e $75 \pm 5 \%$ de umidade relativa) durante 30 dias.

Para avaliar a resistência da madeira foram computados a perda de massa, o desgaste provocado e a porcentagem de mortalidade dos cupins. A quantidade de madeira consumida foi avaliada com base na massa anidra dos corpos-de-prova, tomada antes e após os ensaios. As perdas, a exemplo do ensaio com fungos, foram corrigidas. $\mathrm{O}$ desgaste da madeira provocado pelos cupins e a porcentagem de mortalidade foram avaliados conforme recomendado pela ASTM D-3345 e apresentados nos Quadros 2 e 3, respectivamente.

\subsection{Análise dos Resultados}

Para avaliar a resistência da madeira de $C$. maculata aos fungos, além dos valores de classes de resistência apresentados no Quadro 1, foi empregado o delineamento

R. Árvore, Viçosa-M G, v.26, n.6, p.761-767, 2002 
inteiramente casualizado, com arranjo fatorial, em que foram analisados os seguintes fatores: fungos xilófagos, com três fatores; posição na direção medula-casca, com quatro fatores; e a interação entre os fatores.

Quadro 1 - Classes de resistência da madeira a fungos xilófagos

Table l-Wood resistance classes to wood-destroying fungi

\begin{tabular}{|l|c|c|}
\hline $\begin{array}{c}\text { Classes de Resistência } \\
\text { da Madeira }\end{array}$ & $\begin{array}{c}\text { Perda de Massa } \\
(\%)\end{array}$ & $\begin{array}{c}\text { Massa Residual } \\
(\%)\end{array}$ \\
\hline Altamente resistente & $0-10$ & $90-100$ \\
Resistente & $11-24$ & $76-89$ \\
Resistência moderada & $25-44$ & $56-75$ \\
Não-resistente & $\geq 45$ & $\leq 55$ \\
\hline
\end{tabular}

Para os cupins, por causa da subjetividade dos dados de desgastes e da ampla variação dos dados de porcentagem de mortalidade (Quadros 2 e 3 , respectivamente), optou-se pela análise estatística dos dados de perda de massa (delineamento proposto) e pela utilização das informações do desgaste e da mortalidade para auxiliarem nas interpretações dos resultados.

Quadro 2 - Avaliação do desgaste provocado pelos cupins aos corpos-de-prova

Table 2 -Evaluation of waste caused by termites to test samples

\begin{tabular}{|l|c|}
\hline \multicolumn{1}{|c|}{ Tipo de Desgaste } & Nota \\
\hline Sadio, permitindo escarificações superficiais & 10 \\
Ataque superficial & 9 \\
Ataque moderado, havendo penetração & 7 \\
Ataque intenso & 4 \\
Quebra, havendo ruptura dos corpos-de-prova & 0 \\
\hline
\end{tabular}

Quadro 3 - Avaliação da resistência a cupins subterrâneos, pela porcentagem de mortalidade dos insetos

Table 3 - Resistance to subterranean termites by percentage of insect mortality

\begin{tabular}{|l|c|}
\hline Avaliação & Mortalidade (\%) \\
\hline Baixa & $0-33$ \\
Moderada & $34-66$ \\
Alta & $67-99$ \\
\hline Total & 100 \\
\hline
\end{tabular}

Para possibilitar as análises os dados foram transformados em raiz (perda de massa $+0,5$ ), para o ensaio com fungos, e em arcsen [raiz quadrada (perda de massa/ 100)], para o ensaio com cupins. As transformações dos dados, sugeridas por Steel \& Torrie (1980), foram necessárias para permitir a homogeneidade das variâncias. Na análise e avaliação dos ensaios empregou-se o teste de Tukey, $5 \%$ de probabilidade, para as fontes de variação detectadas como significativas (teste de F).

Para auxiliar nas interpretações dos resultados, foram utilizados os valores médios da densidade da madeira para cada posição na direção medula-casca.

\section{RESULTADOS E DISCUSSÃO}

\subsection{Resistência a Fungos Xilófagos}

Os valores médios da densidade $\left(\mathrm{g} / \mathrm{cm}^{3}\right)$ e da perda de massa (\%) sofrida pela degradação provocada pelos fungos xilófagos testados, para cada posição na direção medula-casca da madeira de C. maculata, encontram-se no Quadro 4.

Quadro 4 - Valores médios da densidade $\left(\mathrm{g} / \mathrm{cm}^{3}\right)$ e da perda de massa (\%) provocada pelos fungos aos corpos-de-prova na direção medula-casca

Table 4-Average values of density $\left(\mathrm{g} / \mathrm{cm}^{3}\right)$ and weight loss (\%) caused by fungi to test samples in pith to bark direction

\begin{tabular}{|l|c|c|c|r|r|}
\hline \multirow{2}{*}{$\begin{array}{c}\text { Posições na } \\
\text { Madeira }\end{array}$} & $\begin{array}{c}\text { Densidade da } \\
\text { Madeira }\left(\mathrm{g} / \mathrm{cm}^{3}\right)\end{array}$ & \multicolumn{2}{|c|}{ Média da Perda de Massa para os Fungos Testados $(\%)$} & \multirow{2}{*}{$\begin{array}{c}\text { Médias } \\
(\%)\end{array}$} \\
\cline { 3 - 6 } & P. placenta & N. lepideus & P. fumosus & 7,12 & 6,18 \\
1 - Interna & 0,88 & 6,94 & 4,48 & 4,81 & 4,71 \\
2 - Média interna & 0,90 & 5,12 & 4,19 & 9,75 & 10,67 \\
3 - Média externa & 0,97 & 11,66 & 10,59 & 13,83 & 19,97 \\
4 - Externa & 0,99 & 20,62 & 25,46 & 8,88 & 10,38 \\
\hline \multicolumn{1}{|c|}{ Médias (\%) } & 0,94 & 11,09 & 11,18 & & \\
\hline
\end{tabular}


Nota-se que os fungos atacaram preferencialmente as partes mais externas da peça que era exclusivamente alburno. Com base nos valores apresentados no Quadro 1, a madeira do cerne interno (posições $1 \mathrm{e}$ 2) de C. maculata é classificada como altamente resistente e a do cerne externo e a do alburno (posições 3 e 4), como resistentes aos fungos testados.

A resistência natural da madeira de $C$. maculata apresentou relação inversa com a densidade, sendo as partes menos densas as mais resistentes à deterioração biológica.

A madeira de alburno de Pinus sp., utilizada como padrão de comparação, sofreu perda de massa de 31,38 , 35,70 e $17,54 \%$, respectivamente, para os fungos $P$. placenta, $N$. lepideus e $P$. fumosus, com média de $28,21 \%$ para os fungos testados, e foi classificada como de resistência moderada. Entretanto, como essa madeira é suscetível ao ataque de fungos xilófagos, a explicação para esses resultados deve-se à interrupção do experimento depois de 12 semanas, não seguindo a recomendação para encerrar o ensaio somente após se detectar uma perda de massa, nas amostras de Pinus sp., superior a 60\% (Jankowsky, 1986; Paes, 1997).

A análise de variância revelou resultados significativos pelo teste de F para os fungos, para as posições nas peças e para a interação desses fatores. O efeito da interação foi desdobrado e analisado pelo teste de Tukey (Quadro 5).

Pela análise do efeito das posições na madeira na resistência ao apodrecimento, observou-se que o ataque foi mais severo nos corpos-de-prova retirados do alburno. Tal fato ocorreu para todos os fungos testados, porém o fungo $P$. fumosus degradou as amostras retiradas as posições 3 e 4 com a mesma intensidade.

Quadro 5 - Comparações múltiplas entre médias, pelo teste de Tukey, para a perda de massa (\%) provocada pelos fungos Table 5 - Multiple comparisons among averages, by the Tukey's test, of weight loss (\%), due the fungi attack

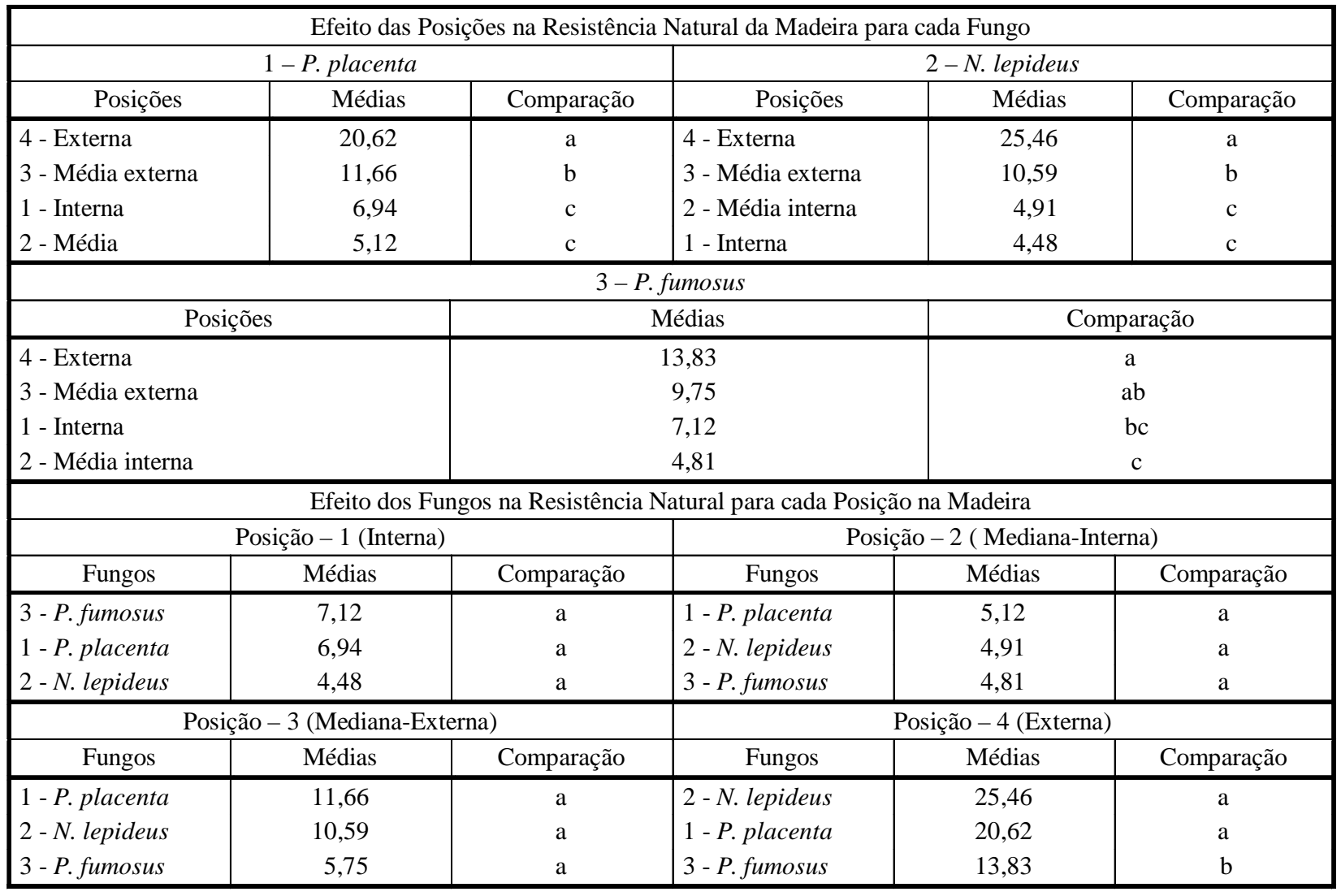

As médias seguidas pela mesma letra não diferem entre si, a $5 \%$ de probabilidade. 
Para os fungos testados, as amostras retiradas nas posições 1 e 2 (posições interna e mediana-interna, respectivamente) foram menos atacadas. Para o fungo $P$. fumosus, as amostras retiradas nas posições 1 e 3 (respectivamente, posições interna e mediana-externa) não diferiram estatisticamente. Para os demais fungos, a posição 3 (mediana-externa) diferiu estatisticamente das demais, e apresentou um comportamento intermediário entre as outras posições na madeira.

Panshin \& De Zeeuw (1980), Hillis (1984), Willeitner (1984) e Findlay (1985) afirmam ser a posição mais externa do cerne (posição 3) a mais resistente aos organismos xilófagos. Neste teste, os resultados não confirmaram a afirmação desses autores, uma vez que as porções mais resistentes foram a 1 e a 2 (respectivamente, posições interna e mediana-interna). A discrepância entre os resultados encontrados e os defendidos pelos autores citados talvez possa estar relacionada à presença de alguma porção de alburno nas amostras obtidas na posição 3. Uma outra possibilidade é a existência de maior concentração de extrativos tóxicos aos fungos testados nas posições mais internas da árvore de crescimento mais rápido, nas condições brasileiras.

Para o efeito dos fungos na resistência natural à deterioração em cada posição na madeira, notou-se que as amostras retiradas nas posições 1,2 e 3 (respectivamente, posições interna, mediana-interna e medianaexterna) apresentaram resistência similar à deterioração provocada pelos fungos testados. Porém, para a posição 4 (posição externa) o fungo $P$. fumosus causou menor deterioração que os demais, o que indica que o fungo desenvolveu-se mais lentamente na madeira.

\subsection{Resistência a Cupins Subterrâneos}

Pela análise das notas de desgaste apresentadas no Quadro 6 e com base nas notas da ASTM D-3345 (1994), no Quadro 4, conclui-se que a madeira de C. maculata praticamente não foi atacada pelos cupins.

Com relação à mortalidade dos cupins, observouse que a madeira comportou-se como resistente, pois causou mortalidade total dos insetos submetidos ao teste (Quadro 5). A natureza e a concentração dos extrativos presentes no lenho talvez tenham sido a causa da mortalidade dos cupins.

A análise de variância dos dados de perda de massa (\%) não revelou diferenças significativas pelo teste de F, para o efeito das posições na direção medula-casca. A baixa perda de massa também é indício de que a madeira ensaiada era resistente aos cupins do gênero Nasutitermes.

Quadro 6 - Médias do desgaste, da mortalidade (\%) e da perda de massa (\%) dos corpos-de-prova na posição medula-casca

Table 6 - Average of waste, of mortality (\%) and weight loss (\%) of test samples in pith to bark position

\begin{tabular}{|l|c|c|c|}
\hline Posições da Madeira & $\begin{array}{c}\text { Desgaste } \\
\text { (Nota) }\end{array}$ & $\begin{array}{c}\text { Mortalidade } \\
(\%)\end{array}$ & $\begin{array}{c}\text { Perda de } \\
\text { Massa (\%) }\end{array}$ \\
\hline 1 - Interna & 9,25 & 100 & 4,99 \\
2 - Média interna & 9,25 & 100 & 4,30 \\
3 - Média externa & 9,13 & 100 & 5,87 \\
4 - Externa & 9,50 & 100 & 6,81 \\
\hline \multicolumn{1}{|c|}{ Médias } & 9,28 & 100 & 5,49 \\
\hline
\end{tabular}

\section{CONCLUSÕES}

A madeira de alburno foi a mais deteriorada pelos fungos, sendo $N$. lepideus o mais ativo na deterioração da madeira testada. De modo geral, as posições mais internas do tronco do E. maculata foram altamente resistentes e as mais externas, resistentes.

$\mathrm{O}$ dano pelos cupins à madeira de $C$. maculata foi somente superficial. Assim, a madeira comportou-se como resistente à ação desses insetos.

O alburno de C. maculata foi atacado por coleobrocas (Lyctus sp.), como observado no Laboratório de Propriedades Físicas e Mecânicas da Madeira da Universidade Federal de Viçosa. Assim, um tratamento preservativo de peças roliças como moirões de cerca, postes, pilares etc. é recomendado para evitar a deterioração de peças postas em serviço, o que irá onerar o custo de manutenção das construções.

\section{REFERÊNCIAS BIBLIOGRÁFICAS}

AGUIAR, O. J. R. Métodos para controle das rachaduras de topo em toras de Eucalyptus grandis W. Hill ex Maiden, visando à produção de laminas por desenrolamento. Piracicaba: USP/ESALQ, 1986. 92 p. Dissertação (Mestrado em Engenharia Florestal) Universidade de São Paulo, Escola Superior de Agricultura "Luiz de Queiroz", 1986. 
AMERICAN SOCIETY FOR TESTING AND

MATERIALS - ASTM D-3345. Standard method for laboratory evaluation of wood and other cellulosic materials for resistance to termite. Annual Book of ASTM Standard, v. 0410, p. 439-441, 1994.

\section{AMERICAN SOCIETY FOR TESTING AND MATERIALS}

- ASTM D-2017 - Standard method of accelerated laboratory test of natural decay resistance of wood. Annual Book of ASTM Standard, v. 0410, p. 324-328, 1994.

AMERICAN SOCIETY FOR TESTING AND MATERIALS - ASTM D-1413 - Standard test method for wood preservatives by laboratory soil-block cultures. Annual Book of ASTM Standard, v. 0410, p. 119-121, 1994.

COUTO, H. T. Z. Manejo de floresta e sua utilização em serraria. In: SEMINÁRIO INTERNACIONAL DE UTILIZAÇÃO DA MADEIRA DE EUCALIPTO PARA SERRARIA, 1995, São Paulo. Anais... São Paulo: LCF/ ESALQ/USP, 1995. p. 20-30.

DELLA LUCIA, M. A. Histórico da política da cultura do eucalipto. Informe Agropecuário, v. 12, n. 141, p. 3-4, 1986.

FINDLAY, W. P. K. The nature and durability of wood. In: FINDLAY, W. P. K. (Ed.). Preservation of timber in the tropics. Dordrecht: Martinus Nijhoff/Dr. W. Junk Publishers, 1985. p. 1-13.

HILLIS, W. E. Wood quality and utilization. In: HILLIS, W.E.; BROWN, A.G. (Eds.). Eucalypts for wood production. Sydney: CSIRO/Academic Press, 1984. p. 159-289.

HUNT, G. M.; GARRATT, G. A. Wood preservation. 3.ed. New York: Mc Graw Hill, 1967. 433 p.

JANKOWSKY, I. P. Potencialidade do creosoto de Eucalyptus spp. como preservativos para madeiras. São Paulo: USP/EP., 1986, 159 p. Tese (Doutorado em Engenharia) - Universidade de São Paulo, Escola Politécnica, 1986.
LELLES, J. G.; REZENDE, J. L. P. Considerações gerais sobre tratamento preservativo da madeira de eucalipto. Informe Agropecuário, v. 12, n. 141, p. 83-90, 1986.

LEPAGE, E. S. Química da madeira. In: LEPAGE, E.S. (Coord.). Manual de preservação de madeiras. São Paulo: IPT, 1986. v. 1. p. 69-97.

PAES, J. B. Efeitos da purificação e do enriquecimento do creosoto vegetal em suas propriedades preservativas. Viçosa: UFV, 1997. 143 p. Tese (Doutorado em Ciência Florestal) - Universidade Federal de Viçosa, 1997.

PANSHIN, A. J.; DE ZEEUW, C. Textbook of wood technology. 4.ed. New York: Mc Graw Hill, 1980. 722 p.

REZENDE, G. C. Implantação e produtividade de florestas para fins energéticos. In: PENEDO, W.R. Gaseificação de madeira e carvão vegetal. Belo Horizonte: CETEC, 1981. p. 9-24. (Série de Publicações Técnicas, 4).

SCHEFFER, T. C. Microbiological degradation and its casual organisms. In: NICHOLAS, D. D. (Ed.). Wood deterioration and its prevention treatments: degradation and protection of wood. Syracuse: Syracuse University, 1973. v. 2. p. 31-106.

SILVA, E. Os plantios florestais no Brasil. In: CONGRESSO FLORESTAL BRASILEIRO, 4.; e CONGRESSO FLORESTAL PANAMERICANO, 1., 1993, Curitiba. Anais... Curitiba: SBS/SBEF, 1993, v. 2. p. 719.

STEEL, R. G. D.; TORRIE, J. H. Principles and procedures of statistic: a biometrical approach. 2.ed. New York: Mc Graw Hill, 1980. 633 p.

VITAL, B. R.; DELLA LUCIA, R. M. Propriedades físicas e mecânicas da madeira de eucalipto. Informe Agropecuário, v. 12, n. 141, p. 71-74, 1986.

WILLEITNER, H. Laboratory tests on the natural durability of timber-methods and problems. Stockholm: The International Research Group on Wood Preservation, 1984. 11 p. (Doc. IRG/WP/2217). 